\title{
Progress toward the synthesis of the bicyclo (6.3.0) framework using TMM diyls
}

\author{
Joohee Hong, Richard Yee, and R. Daniel Little* \\ Department of Chemistry and Biochemistry, University of California Santa Barbara, \\ Santa Barbara, CA 93106, USA \\ E-mail: little@chem.ucsb.edu
}

Dedicated to Professor Atta-ur-Rahman on the occasion of his $65^{\text {th }}$ Birthday

\begin{abstract}
The ability of a vinylcyclopropyl substituted TMM diradical (e.g. 1) to transform to the bicyclo (6.3.0) framework is not restricted to cis cyclopropanes. Trans substituted systems work well, thereby significantly increasing the scope of the chemistry. Improved levels of regioselection toward the (6.3.0) system were observed. A mechanistic rationale for the increase is presented.
\end{abstract}

Keywords: Trans-substituted TMM diyls, bicyclo (6.3.0) framework, 8-membered rings

\section{Introduction}

In 1998, we reported a new route to 8-membered rings that featured the intriguing trimethylenemethane (TMM) diyl 1. ${ }^{1}$ This diradical can be viewed as a hybrid of several wellknown intermediates whose chemistries have been thoroughly characterized, viz. a vinylcyclopropane, cyclopropylcarbinyl radical, and a divinylcyclopropane. ${ }^{2}$ The diyls are accessed from bicyclic diazenes. When diazene 2, for example, is heated in refluxing benzene, it is smoothly transformed to the bicyclo (6.3.0) and (4.3.0) adducts $\mathbf{3}$ and $\mathbf{4}$, respectively. While selective for the formation of the 8-membered ring, the selectivity is too low to be of synthetic utility. Since our ultimate objective is to apply the chemistry to the synthesis of bioactive natural products containing the (6.3.0) framework, it is incumbent upon us to develop strategies whereby the selectivity can be increased to synthetically useful levels. ${ }^{3}$ Herein we describe our efforts to date.

While a detailed mechanism for the transformation of $\mathbf{2}$ to $\mathbf{3}$ and $\mathbf{4}$ has not been elucidated, ${ }^{4,5}$ we offer two possibilities: (1) ring opening of the cyclopropane in diyl $\mathbf{5}$ to afford the distonic diyl 6 followed by radical recombination leading to the (6.3.0) and (4.3.0) frameworks 3 and 4 (pathway A of Scheme 2), or (2) cyclization of the TMM diyl 6 onto $\mathrm{C}_{\mathrm{x}}$ of 
the pendant alkene followed by ring opening of the resulting cyclopropylcarbinyl diradical 7 and collapse to form the (6.3.0) adduct 3 (pathway B). ${ }^{6}$ This pathway requires the presence of a cissubstituted cyclopropane so that the requisite centers, $C_{r}$ and $C_{x}$, can reach one another. This has been the case for each of the systems we have described thus far; that is, only cis substituted cyclopropanes have been explored. Pathway A, on the other hand, is not restricted in this manner - either a cis or a trans substituted cyclopropane will do. Herein we report (a) a test of whether the chemistry is hampered by the restrictions imposed by pathway B, (b) the chemistry of the first trans substituted cyclopropyl diyl, (c) an improvement in regioselectivity, and (d) a mechanistic rationale for the increase. We close by offering some future prospects for the chemistry.

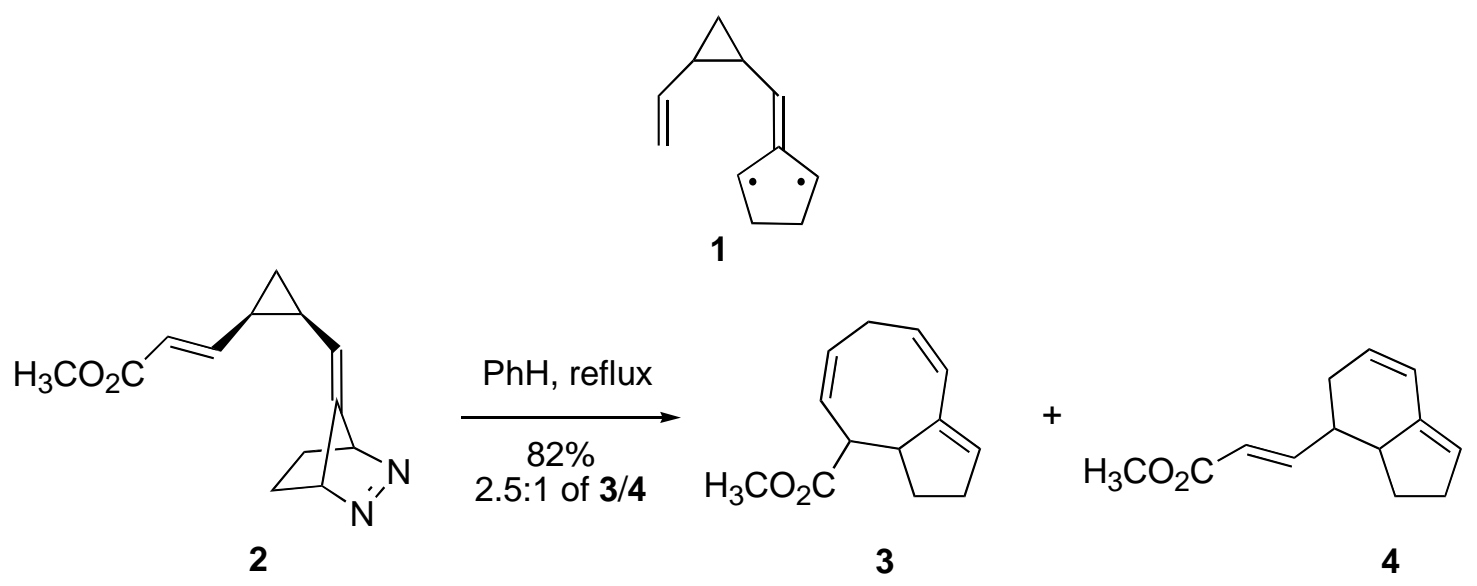

Scheme 1. Intriguing diyl 1 and an expression of its chemistry.

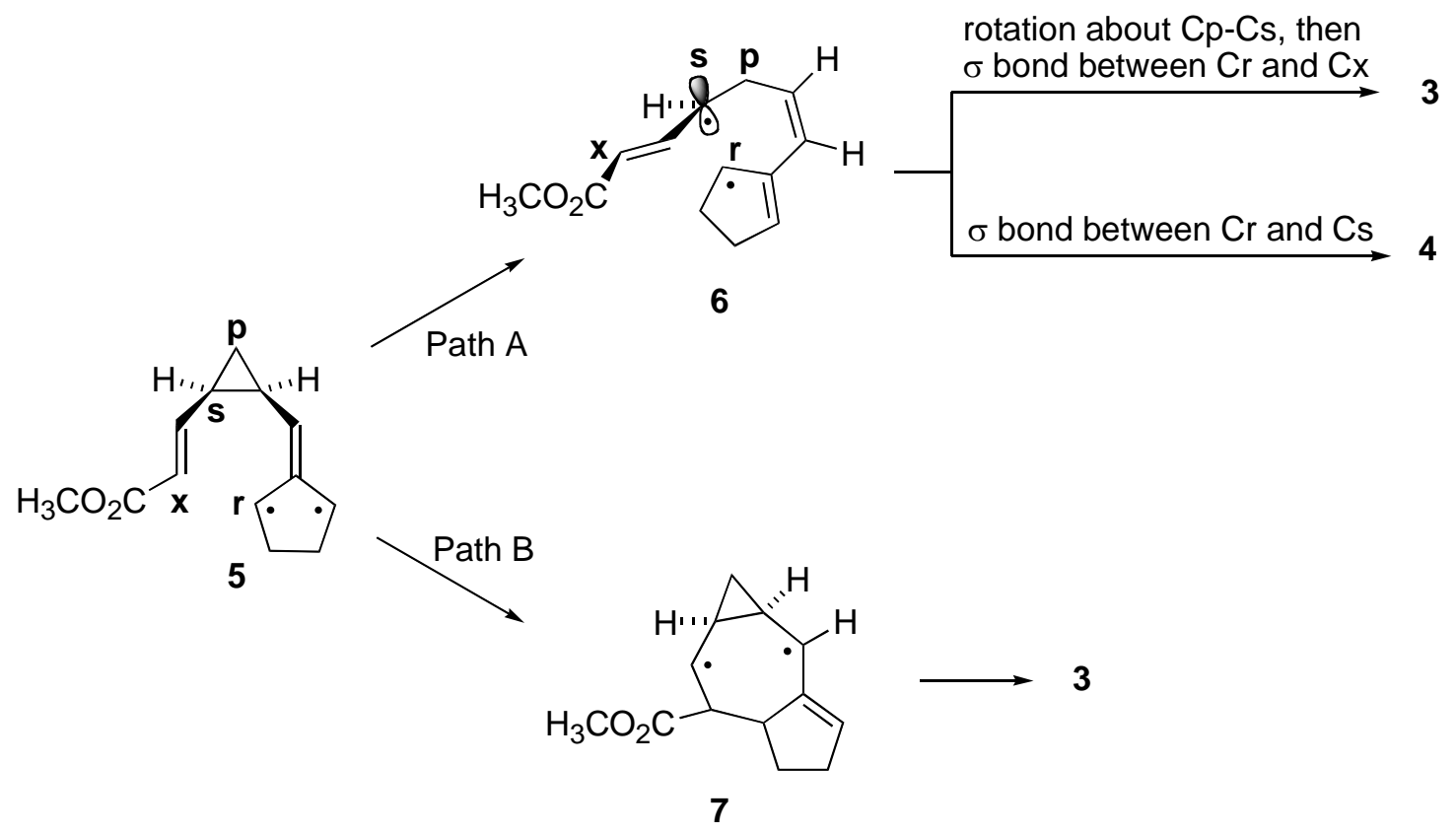

Scheme 2. Alternative mechanistic pathways. 


\section{Results and Discussion}

We elected to synthesize diazene 12 since, for reasons that are delineated below, we thought that the resulting diyl would transform to the (6.3.0) framework with increased selectivity. The synthesis began with the known vinyl alcohol 8 (trans/cis 4:1). ${ }^{7}$ Ozonolytic cleavage of the C$\mathrm{C} \pi$ bond led to the expected aldehyde in a $67 \%$ yield. At this point the cis and trans isomers were easily separated chromatographically, and the pure trans isomer $\mathbf{9}$ was used to move forward. Conversion of the trans aldehyde to fulvene $\mathbf{1 0}$ proceeded uneventfully $(\mathrm{CpH}, \mathrm{i}-\mathrm{PrOH}$, pyrrolidine; AcOH), ${ }^{8}$ albeit in only a 53\% yield. Subsequent cycloaddition using DEAD in methylene chloride, reduction of the $\Delta-4,5 \pi$ bond of the resulting Diels-Alder adduct using diimide, and conversion of the biscarbamate functionality into that of a diazene, afforded $\mathbf{1 1}$ (20\% over 4 steps). Swern oxidation followed by Horner-Emmons-Wadsworth olefination provided 12, the system whose chemistry we wished to study.

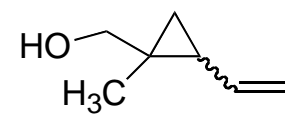

$8(\sim 4: 1$ trans to cis)

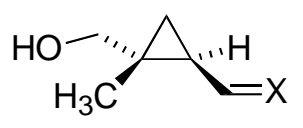

9, $\mathrm{X}=\mathrm{O}$

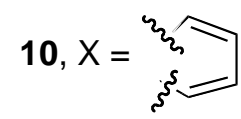

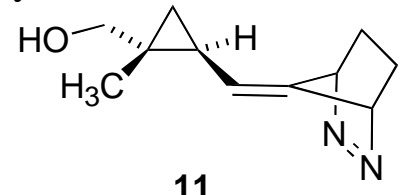

11

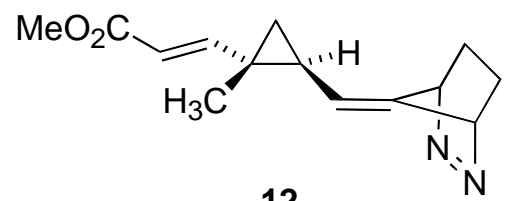

Scheme 3. Important structures for the synthesis of diyl precursor 12.

A dilute benzene solution of diazene $12(12.5 \mathrm{mM})$ was added over $1 \mathrm{~h}$ to a solution of refluxing benzene. When the addition was complete, reflux was continued for another half hour before cooling the solution to room temperature. Removal of the solvent followed by chromatography led to the isolation of adducts 14 and 15 in a combined yield of 80\%. The 5:1 preference for 14, the (6.3.0) adduct, exceeds the level obtained in each of our previous investigations where the values generally hovered around 2.5:1. ${ }^{1}$ Of added interest is the fact that 14 occurs as a single diastereomer. Extensive decoupling experiments allowed us to determine the magnitude of the coupling constants between $\mathrm{H}_{\mathrm{b}}$ and its neighbors, $\mathrm{H}_{\mathrm{a}}(\mathrm{J}=7 \mathrm{~Hz})$ and $\mathrm{H}_{\mathrm{c}}(\mathrm{J}=$ $11 \mathrm{~Hz}$ ). Their magnitudes, coupled with the results of molecular mechanics calculations, rule out the diastereomeric structure where the configuration at the ester bearing carbon is reversed. Thus, the calculated dihedral angle between $\mathrm{H}_{\mathrm{a}}$ and $\mathrm{H}_{\mathrm{b}}$, and between $\mathrm{H}_{\mathrm{a}}$ and $\mathrm{H}_{\mathrm{c}}$ are $\sim 133^{\circ}$ and $168^{\circ}$, respectively, in structure 14 while they are $\sim 5.4^{\circ}$ and $73^{\circ}$ in the diastereomer. The latter scenario predicts one large and one small coupling constant, and is not in accord with the results. 


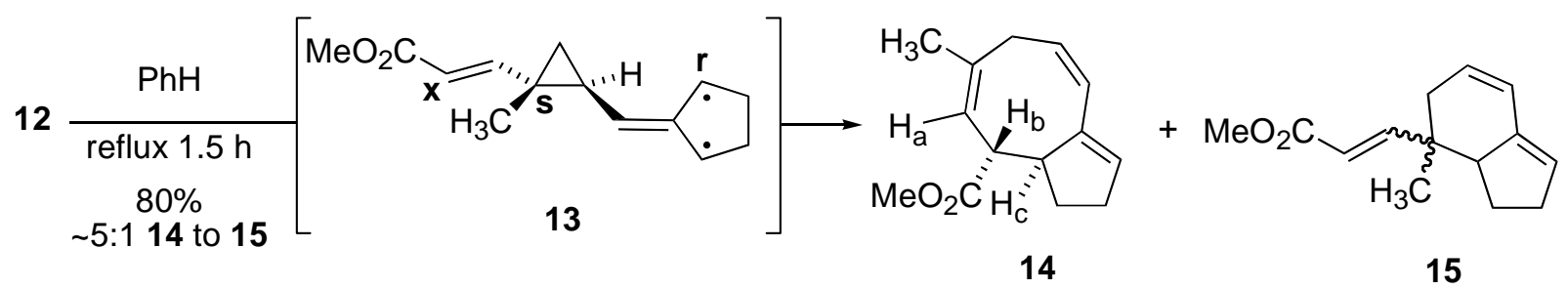

Scheme 4. Improved regioselectivity in the chemistry of diyl 13.

This transformation clearly demonstrates that the chemistry is not restricted to cis substituted cyclopropanes; trans substituted systems work equally well. In this instance, we confidently conclude that pathway B (Scheme 2) is not operable since the requisite carbon atoms $\left(C_{r}\right.$ and $C_{x}$ in 13) are on opposite sides of the 3-membered ring and therefore cannot reach one another.

We cautiously suggest that the increase in regioselectivity may be correlated with an increase in the activation barrier leading to the (4.3.0) adduct 15, rather than to a decrease in the barrier leading to the (6.3.0) framework. As shown in Figure 1, neither of the transition structures leading to the (4.3.0) skeleton, 16 or $\mathbf{1 7}$ can escape the existence of an energy raising non-bonded interaction between the 5-membered ring and either the ester unit (see 16) or the methyl group (see 17).

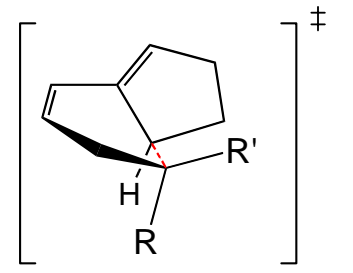

16, $\mathrm{R}=\mathrm{CH}_{3}, \mathrm{R}^{\prime}=\mathrm{CH}=\mathrm{CHCO}_{2} \mathrm{CH}_{3}$

17, $\mathrm{R}=\mathrm{CH}=\mathrm{CHCO}_{2} \mathrm{CH}_{3}, \mathrm{R}^{\prime}=\mathrm{CH}_{3}$

Figure 1. Transition structures leading to the (4.3.0) skeleton.

Additional support for the statement that the transformation is not restricted to cissubstituted cyclopropanes is evident from the efficient conversion of diazene $\mathbf{1 8}$ into a 5:1 mixture of the (6- and (4.3.0) adducts 19 and 20. The result lends additional credibility to mechanistic pathway A shown in Scheme 2.

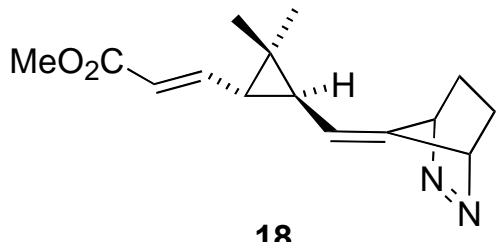

18

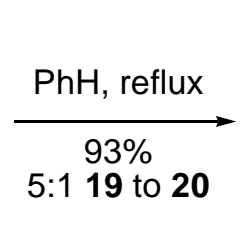

19 to 20

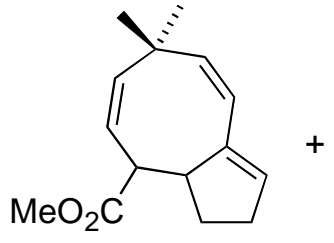

19

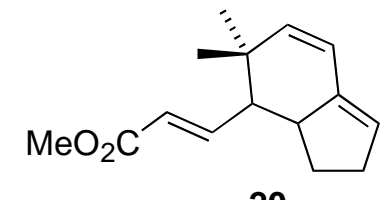

20

Scheme 5. Another example of the transformation of a trans substituted cyclopropyl diyl. 
Gratifyingly, the preference for the 8-membered ring once again exceeds that we have previously encountered. We suggest that the gem methyl groups may facilitate the coiling process that is required in order to bring the reacting centers within bonding distances, in accord with the Thorpe Ingold effect. ${ }^{9}$ The effect should facilitate both the formation of the 6 as well as the 8-membered ring. While an alternative rationale may prove more accurate over time, we suggest that the transition structures leading to the former may suffer non-bonded interactions between one of the methyl groups and the five membered ring thereby, once again, disfavoring cyclization to produce the (6.3.0) framework (see structures 21 and 22).

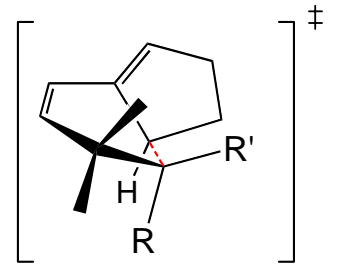

21, $\mathrm{R}=\mathrm{H}, \mathrm{R}^{\prime}=\mathrm{CH}=\mathrm{CHCO}_{2} \mathrm{CH}_{3}$

22, $\mathrm{R}=\mathrm{CH}=\mathrm{CHCO}_{2} \mathrm{CH}_{3}, \mathrm{R}^{\prime}=\mathrm{H}$

Figure 2. Non-bonded interactions in the transition structures leading to the (4.3.0) framework.

\section{Conclusions}

While we have been able to improve the regioselectivity, we have a long way to go before reaching synthetically useful values. Nevertheless, we feel that the present investigation is of value for several additional reasons. First, if our hypothesis is correct, then by further increasing the size of the substituent appended to $C_{s}$ of the diyl, the bias for forming the (6.3.0) framework will increase. We see no need to blindly increase the size to t-butyl, for example, just to prove the point. Rather, we are intrigued by the opportunity to use a surrogate of similar size that bears usable functionality, a ketal for example, which could be transformed at a later stage in a sequence. Secondly, and of greater significance, is the demonstration that the chemistry of TMM diyls 1 (Scheme 1) is not limited in scope to cis-substituted cyclopropanes; trans work just as well. Additional studies are in progress and will be reported in due course.

\section{Experimental Section}

General Procedures. Moisture and air sensitive reactions were conducted using flame-dried glassware under a nitrogen atmosphere. "Removed under reduced pressure" or "concentrated in vacuo" refers to the removal of solvent using a rotary evaporator. Reagents were purchased and used without further purification. Tetrahydrofuran (THF) was distilled from sodium/benzophenone ketyl. Thin layer chromatography (TLC) was performed on silica gel coated glass plates (Merck 60F-254). Spots were visualized by staining with vanillin, p- 
anisaldehyde, iodine, or by UV light. Silica gel (ICN 36-63) was used for column chromatography. Infrared (IR) spectra were recorded on a Matson Galaxy Series 2020 FT-IR and are reported in wavenumbers $\left(\mathrm{cm}^{-1}\right) .{ }^{1} \mathrm{H}$ NMR spectra were recorded using Varian unity INOVA at 200 or $400 \mathrm{MHz}$ in $\mathrm{CDCl}_{3}$ with chemical shifts being reported in ppm. Coupling constants are reported in Hz. ${ }^{13} \mathrm{C}$ NMR spectra were recorded at 50 or $100 \mathrm{MHz}$ in $\mathrm{CDCl}_{3}$. Mass spectra were recorded by Dr. James Pavlovich using a VG 70-250E double focusing magnetic sector instrument with an EI source. GCMS spectra were recorded using a Hewlett Packard series II 5890 Plus.

(1-Methyl-2-vinylcyclopropyl)methanol (8). Vinylcyclopropane 8 was synthesized by following the procedure described by Schaumann and co-workers. ${ }^{7}$

2-[(2,3-Diazabicyclo[2.2.1]hept-2-en-7-ylidenemethyl)-1-methylcyclopropyl methanol (11), 3-[3-(2,3-Diazabicyclo[2.2.1]hept-2-en-7-ylidenemethyl)-1-methylcyclopropyl] acrylic acid methyl ester (12), 3-[3-(2,3-Diazabicyclo[2.2.1]hept-2-en-7-ylidenemethyl)-2,2-dimethylcyclopropyl] acrylic acid methyl ester (18). The conversion of 8 to diazenes 11 and 12 were conducted in accord with detailed procedures we have previously published. The spectral data for diazene 11 is: ${ }^{1} \mathrm{H}$ NMR (400 MHz, $\mathrm{CDCl}_{3}$ ) $\delta 5.47$ (d, J = $\left.2 \mathrm{~Hz}, 1 \mathrm{H}\right), 5.11$ (d, J = $2 \mathrm{~Hz}, 1 \mathrm{H}$ ), $4.82(\mathrm{~d}, \mathrm{~J}=9 \mathrm{~Hz}, 1 \mathrm{H}), 3.40$ and 3.34 (d, $\mathrm{J}=11 \mathrm{~Hz}, 2$ diastereotopic $\mathrm{H}), 1.64-1.63$ (m, 3H), 1.33 (ddd, J = 9 Hz, 9 Hz, 5.5 Hz, 1H), 1.10 (m, 2H), 1.07 (s, 3H), 0.85 (dd, J = 9 Hz, 4.5 Hz, 1H), 0.32 (dd, J = 5.5 Hz, $4.5 \mathrm{~Hz}, 1 \mathrm{H}) ;{ }^{13} \mathrm{C} \mathrm{NMR}\left(100 \mathrm{MHz}, \mathrm{CDCl}_{3}\right) \delta 145.1,128.5,116.8,94.5,70.8$, 24.7, 21.5, 21.0, 20.9, 16.1; FTIR (neat, $\mathrm{NaCl}, \mathrm{cm}^{-1}$ ) 3410, 3074, 2963; HRMS (EI; (m/z): [M$\left.\mathrm{N}_{2}\right]+$ calculated for $\mathrm{C}_{11} \mathrm{H}_{16} \mathrm{O}$ 164.1196, found 164.1201; for diazene 12: ${ }^{1} \mathrm{H}$ NMR (400 MHz, $\left.\mathrm{CDCl}_{3}\right) \delta 6.46$ (d, J = $12.6 \mathrm{~Hz}, 1 \mathrm{H}, \beta$-vinyl), 5.73 (d, J = 12.6 Hz, 1H, $\alpha$-vinyl), 5.41 (s, $\left.1 \mathrm{H}\right), 5.12$ (s, 1H), 4.85 (d, J = 7.2 Hz, 1H), 3.75 (s, 3H, $\mathrm{CO}_{2} \mathrm{CH}_{3}$ ), 1.70-1.65 (m, 2H), 1.58 (s, 2H), 1.311.27 (m, 1H), 1.26 (s, 2H), 1.16 (s, 3H, methyl), 0.82 (dd, J = 5.6 Hz, 1H); ${ }^{13} \mathrm{C} \mathrm{NMR}(100 \mathrm{MHz}$, $\left.\mathrm{CDCl}_{3}\right) \delta 167.3,156.4,147.1,116.5,114.9,76.9 ; \mathrm{HRMS}\left(\mathrm{EI} ;(\mathrm{m} / \mathrm{z}):\left[\mathrm{M}-\mathrm{N}_{2}\right]+\right.$ calculated for $\mathrm{C}_{14} \mathrm{H}_{18} \mathrm{O}_{2}$ 218.13013, found 218.13019; for diazene 18: ${ }^{1} \mathrm{H}$ NMR (400 MHz, $\left.\mathrm{CDCl}_{3}\right) \delta$ 6.72-6.64 (m, 1H), 5.90 (d, 1H, J = 15.3 Hz), 5.12 (d, 1H, J = $1.60 \mathrm{~Hz}$ ), 5.03 (d, 1H, J = 5.74 Hz), 4.89 (d, $1 \mathrm{H}, \mathrm{J}=8.94 \mathrm{~Hz}$ ), 3.72 (s, 3H), 1.65-1.69 (dd, 1H, J = $4.5 \mathrm{~Hz}, 15 \mathrm{~Hz}$ ), 1.40-1.42 (dd, 1H, J = 4.5 $\mathrm{Hz}, 9), 1.38-1.41$ (m, 4H), 1.25 (s, 3H), 1.26 (s, 3H). ${ }^{13} \mathrm{C}$ NMR (100 MHz, $\left.\mathrm{CDCl}_{3}\right) \delta 166.8$, 150.7, 144.7, 118.7, 118.6, 118.0, 72.8, 51.4, 23.6, 22.3, 21.4, 20.9, 16.5, 14.0, 14.2. FTIR (neat, $\mathrm{NaCl}, \mathrm{cm}^{-1}$ ) 3054, 3021, 2985, 2965, 2835, 2741, 1716. HRMS (EI; (m/z): [M-N $]+$ calculated for $\mathrm{C}_{15} \mathrm{H}_{20} \mathrm{O}_{2}$ 232.14578, found 232.15984.

6-Methyl-3, 3a, 4, 7-tetrahydro-2H-cyclopentacyclooctene-4-carboxylic acid methyl ester (14). A $100 \mathrm{~mL}$ round-bottom flask was charged with benzene $(60 \mathrm{~mL})$ and degassed with argon for $1 \mathrm{~h}$. An addition funnel containing $0.031 \mathrm{~g}, 0.125 \mathrm{mmol}$ ) of diazene 12 dissolved in $10 \mathrm{~mL}$ of degassed benzene was attached to the top of a reflux condenser. The solution was added dropwise through the condenser in order to keep the diazene as cool as possible prior, over a $1 \mathrm{~h}$ period. When the addition was complete, the funnel was rinsed with additional benzene. Reflux was continued for an additional half hour, the solution was cooled to room temperature and the 
solvent was removed in vacuo. Chromatography over silica gel using 5\% EtOAc in hexanes as the eluent led to the separation of adducts $\mathbf{1 4}$ and $\mathbf{1 5}$ (5:1 ratio) in a combined yield of $80 \%$. The proton NMR assignments for $\mathbf{1 4}$ are based upon extensive decoupling experiments and are as follows: ${ }^{1} \mathrm{H}$ NMR (500 MHz, $\mathrm{CDCl}_{3}$ ) $\delta 6.24$ (d, 1H, J = 11.5, H-9), 5.81 (m, 1H, H-1), 5.27 (d, $1 \mathrm{H}, \mathrm{J}=7 \mathrm{~Hz}, \mathrm{H}-5$ ), 3.97 (dd, 1H, J = $11 \mathrm{~Hz}, 11 \mathrm{~Hz}, \mathrm{H}-3 \mathrm{a}$ ), 3.79-3.71 (m, 2H, H-7), 3.73 (s, 3H, $\mathrm{CO}_{2} \mathrm{CH}_{3}$ ), 3.15 (dd, 1H, J = $\left.11 \mathrm{~Hz}, 7 \mathrm{~Hz}, \mathrm{H}-4\right), 2.38$ (ddd, 1H, J = $17 \mathrm{~Hz}, 13 \mathrm{~Hz}, 9 \mathrm{~Hz}, \mathrm{H}-3$ ), 2.21 (ddd, 2H, J = 13 Hz, 9 Hz, 5 Hz, H-2), 2.12 (m, 1H, H-3), 1.73 (s, 3H, C-10 Me); ${ }^{13} \mathrm{C}$ NMR (125 $\left.\mathrm{MHz} \mathrm{CDCl}_{3}\right) \delta 174.7,142.3,134.7,129.3$, two very closely spaced peaks at $\sim 127.8,119.5,51.9$, 51.5, 45.6, 33.0, 31.3, 28.0, 26.1. For additional detail, please refer to the text.

7, 7-Dimethyl-3, 3a, 4, 7-tetrahydro-2H-cyclopentacyclooctene-4-carboxylic acid methyl ester (19) and 3-(5,5-dimethyl-3, 3a, 4, 5-tetrahydro-2H-inden-4-yl)-acrylic acid methyl ester (20). A $250 \mathrm{~mL}$ round bottom flask was charged with benzene ( $260 \mathrm{~mL}$ ) and degassed with nitrogen for $1 \mathrm{~h}$. A reflux condenser was then attached to the round-bottomed flask and to the top of the condenser was connected a $100 \mathrm{~mL}$ addition funnel. The system was purged with nitrogen. The addition funnel was charged with $0.162 \mathrm{~g}(0.623 \mathrm{mmol})$ of diazene 18 dissolved in previously degassed benzene (52 mL, $12 \mathrm{mM}$ ) via syringe. The benzene in the round-bottomed flask was heated to reflux after which the diazene solution was slowly added in dropwise over $\sim 1.5$ h. The reflux condenser and the addition funnel were oriented to ensure that the diazene solution fell directly into the refluxing benzene without coming into contact with the walls of the reflux condenser or the sides of the flask. After complete addition of the diazene solution, the addition funnel was rinsed with $20 \mathrm{~mL}$ of degassed benzene and allowed to drip into the refluxing benzene. The solution was refluxed for an additional $\sim 1 \mathrm{~h}$ and then cooled to rt. Benzene was removed in vacuo and the crude oil was purified on silica gel (10\% ether/pet ether) to afford pure 19 and pure 20 in a combined yield of 93\% $(0.579 \mathrm{mmol})$ and in the ratio $~ 5: 1$. For the (6.3.0) adduct 19: ${ }^{1} \mathrm{H}$ NMR $\left(400 \mathrm{MHz} \mathrm{CDCl}_{3}\right) \delta 1.21(\mathrm{~s}, 3 \mathrm{H}), 1.27(\mathrm{~s}, 3 \mathrm{H}), 1.38-1.48(\mathrm{~m}$, 1H), 1.53-1.64 (m, 2H), 2.05-1.97 (m, 2H), 2.36-2.32 (m, 2H), 2.80-2.87 (m, 1H), 3.06 (dd, 1H, J $=3 \mathrm{~Hz}, 10.5 \mathrm{~Hz}$ ), 3.671 (s, 3H), 5.11 (d, 1H, J = $11 \mathrm{~Hz}$ ), 5.14 (d, 1H, J = $11 \mathrm{~Hz}$ ), 5.37-5.38 (m, $1 \mathrm{H}), 5.73$ (dd, $1 \mathrm{H}, \mathrm{J}=3 \mathrm{~Hz}, 10 \mathrm{~Hz}), 5.94$ (m, 1H). ${ }^{13} \mathrm{C} \mathrm{NMR}\left(100 \mathrm{MHz}, \mathrm{CDCl}_{3}\right) \delta 174.7,154.3$, 146.3, 131.1, 125.4, 120.6, 120.4, 55.6, 51.9, 51.4, 34.0, 31.9, 29.7, 28.4, 25.7. FTIR 2935, 2849, 1739, 1595, 1465, 1390, 1352, 1249, 1161, 1031, 1010, 720, 750, $685 \mathrm{~cm}^{-1}$. HRMS (EI) (m/z): calculated for $\mathrm{C}_{15} \mathrm{H}_{20} \mathrm{O}_{2}$ 232.14578, found 232.14605. For the (4.3.0) adduct 20: ${ }^{1} \mathrm{H}$ NMR $\left(400 \mathrm{MHz}, \mathrm{CDCl}_{3}\right) \delta 1.19$ (s, 3H), 1.24 (s, 3H), 1.26-1.58 (m, 2H), 2.11-2.18 (m, 1H), 2.72-2.78 (m, 2H), 3.04-3.08 (m, 1H), 3.67 (s, 3H), 5.60-5.62 (m, 1H), 5.74-5.81 (m, 1H), $5.85(\mathrm{~m}, 1 \mathrm{H})$, 6.30-6.32 (d, 1H, J 9.2 Hz), 6.87-7.00 (m, 1H). HRMS (EI) (m/z): calculated for $\mathrm{C}_{15} \mathrm{H}_{20} \mathrm{O}_{2}$ 232.14578, found 232.14564. 


\section{Acknowledgements}

We thank the Petroleum Research Foundation administered by the American Chemical Society (ACS PRF\# 43443-AC1) for supporting this research.

\section{References}

1. Carroll, G. L.; Little, R. D. Tetrahedron Lett. 1998, 39, 1893.

2. (a) Quirante, J. J.; Enriquez, F.; Hernando, J. M. THEOCHEM 1990, 63, 193. (b) Cooksy, A. L.; King, H. F.; Richardson, W. H. J. Org. Chem. 2003, 68(24), 9441. (c) Wender, P. A.; Brighty, K. Tetrahedron Lett. 1988, 29(51), 6741.

3. Petasis, N. A.; Patane, M. A. Tetrahedron, 1992, 48, 5757.

4. (a) Gajewski, J.; Paul, G. J. Org. Chem. 1996, 61, 1399. (b) Gajewski, J.; Paul, G.; Kestyn, P. A.; Khorasanizadeh, S.; Lahti, P. M. J. Org. Chem. 1997, 62, 7189. (c) Adam, W.; Finzel, R. J. Am. Chem. Soc. 1992, 114, 4563.

5. These mechanistic schemes are, admittedly, highly simplified. They ignore potentially important factors including, for example, the diyl spin state and the possibility of ring opening according to pathway A leading to both $\mathrm{E}$ and $\mathrm{Z}$ alkenes. These issues are being addressed.

6. Mikesell, P. J.; Little, R. D. Tetrahedron Lett. 2001, 42, 4095.

7. Schaumann, E.; Kirschning, A.; Narjes, F. J. Org. Chem. 1991, 56, 717.

8. Stone, K. J.; Little, R. D. J. Org. Chem. 1984, 49, 1849.

9. Jung, M. E.; Piizzi, G. Chem. Rev. 2005, 105, 1735.

10. (a) Kim, A.; Carroll, Georgia L.; Little, R. D. Eur. J. Org. Chem. 1998, 1, 1. (b) Little, R. D. Chem. Rev. 1996, 96(1), 93. 